\title{
The Use Of Social Media In Building Interest In Wellness On A College Campus
}

Joseph A. Field, University of North Dakota, USA

Dennis J. Elbert, University of North Dakota, USA

Steven B. Moser, University of North Dakota, USA

\begin{abstract}
The usage of social media networks, such as websites like Facebook, Twitter, and YouTube, had become the number one activity on the internet by 2010. The sweeping increase in usage led organizations to explore the marketing possibilities the networks offered. The turning point occurred when organizations began to ask whether it was feasible to use social media networks as a primary marketing strategy and reduce or ultimately replace traditional marketing efforts. A pilot project focused on a marketing plan that was implemented at a student fitness center, using social media networks as the primary marketing strategy.
\end{abstract}

Keywords: Internet Marketing; Social Media; Promotion; Fitness

\section{INTRODUCTION}

hen does a consumer trend become a legitimate business opportunity? It took radio broadcast 38
years to reach 50 million users; television and internet achieved that same milestone in 13 and four
years, respectively (Qualman, 2009). The social media network called Facebook reached 100
million users in less than nine months (Facebook, 2010). The rapid development between 2005 and 2010 of Facebook and other social media networks, like Twitter and YouTube, led many organizations to examine the marketing potential of these networks. Recent surveys report that $59 \%$ of internet users say that they use at least one social networking site (of adults). This is nearly double the use in 2008. From this survey of 2,255 American adults surveyed between October 20 and November 28, 2010, 92\% are Facebook users, 29\% MySpace users, 18\% LinkedIn users, and 13\% Twitter users (Hampton, Goulett, Rainie, and Purcell, 2011).

Social media networking encompasses the interaction between people with similar interests and activities by communicating and sharing information. Social media networking stems from the concept of networking in inperson situations. The internet, however, provides a platform for individuals to interact with a much larger network on a more frequent basis. There are many ways to interact on the web, including the use of e-mail, instant messaging, blogging, gaming and social media websites. All of these potential interactions are important and significant; however, one - more widely known as social media networks - will be examined in more depth based on its usage and marketing capabilities.

Colleges and universities are faster adopters of social media when compared to the Fortune 500 and Inc. 500. In 2008, $13 \%$ of the Fortune 500 and $39 \%$ of the Inc. 500 had a blog. College admission departments, at the same time, were found in $41 \%$ of the universities and colleges (UMass Dartmouth, 2011). Social media is also looked upon as being more trustworthy than traditional media (Foux, 2006). This is a positive aspect that may help to explain the movement towards this way of reaching consumers.

In order to assess the legitimacy of social media networks and their marketing potential, a pilot project was conducted on a midwestern college campus. The study focused on the feasibility of replacing traditional forms of marketing with social media networks as the primary marketing strategy. The project took place at the main student fitness facility on campus and focused on a marketing plan implemented directly prior to the study. The fitness center was selected for this study because the center had devoted the majority of its marketing strategies to 
traditional media tools (newspaper, radio, brochures, etc.) from its opening to the start of the pilot project. The pilot project will be reviewed in detail in later sections.

\section{SOCIAL MEDIA NETWORK REVIEW}

When reviewing social media networks, it is important to realize that there are literally thousands of social media network options that are used by diverse groups all over the world. On one end of the spectrum, a number of social media networks are quite small and consist of a just a few users in very limited niche markets. On the other hand, there are social media networks that have a broad focus with a countless number of users in every corner of the globe. For the purpose of this study, three social media networks were selected on the basis of size, popularity and growth. The three social media networks are Facebook, Twitter and YouTube. The subsequent sections will give a background on each network and explain how they can each be implemented into an organization's marketing strategy.

\section{Facebook}

With modest beginnings, Facebook started as a small networking website for a few dozen students at Harvard University; that once miniature network quickly turned into an enormous social media network with over 400 million users from more than 100 different countries (Facebook, 2010). When viewed in other terms, if Facebook's users were counted as the population of a country, it would be the world's third largest behind China and India (Qualman, 2009). More remarkable than the number of users was the amount of time it took Facebook to reach 400 million - less than six years.

Advertising on Facebook can be extremely complex, but in basic terms, organizations can place banner advertisements on users' profile pages using text and photos with the goal of driving the suitable users to a corporate Facebook page, website or product. Facebook web banners have the ability to be specific and targeted through the use of demographics from personal information on users' profile pages. For example, Facebook advertising would allow a party store to target users by placing a web banner on a user's profile page on their birthday.

Overall, Facebook has set the standard to which other social media networks aim to achieve. The size, functionality and features on Facebook contributed to the valuable experience the user gains from using this social media network. The marketing potential for organizations to capitalize on the corporate pages and advertising within the network increased its attractiveness from a business standpoint. These are some of the main reasons why Facebook was the most heavily used social media network, but others have sought to match its caliber.

\section{Twitter}

When compared to Facebook's 400 million users, by 2010 Twitter had 75 million users at that same point (Gaudin, 2010). Although Twitter has fewer users, rapid growth occurred in a short span of time leading to several technical and infrastructure problems. During growth periods, in 2009 Twitter actually could not house all of the incoming flow of data and information, which led to frequent blackouts called fail whales. Despite these growing pains, Twitter became an established social media network with many opportunities for users to share information. One such group of users is organizations. Following is a description on how organizations can implement Twitter into their marketing strategy.

Twitter allows organizations of all sizes to reach consumers in a broad spectrum through instant information and feedback. Organizations can use tweets to message consumers with product updates, marketing offers, web exclusives and more (Twitter, 2010). Companies have used Twitter to send product updates to the millions of followers those two companies have amassed. Other organizations have IT twitter teams that monitor complaints and questions and address the issues via Twitter (Twitter, 2010). Organizations also benefit Twitter's opt-in feature that lets users choose who they wish to follow, which makes the marketing less intrusive. Morris (2010) describes Twitter as a "marriage of networking with media... Twitter has become one of the essential tools in enjoying social media and implementing social media in business. The reason for growth and popularity can be its initial ease of use." 
One other major benefit of Twitter is that followers can receive tweets nearly anywhere via their mobile phone device. That means users can update followers instantly with news on product and service offerings without the need of an internet connection. For example, a coffee company could send a tweet that offers a ' $25 \%$ off' drink promotion for that day; so a Twitter follower walking nearby could receive the message via SMS text message and decide to stop in for a drink.

Using Twitter for organizational uses does present some drawbacks. First, as mentioned above, Twitter often experiences "fail whales" where the website will black out due to high usage (Twitter, 2010). Second, although Twitter had 75 million users as of 2010, the number of active users who use Twitter on a regular basis is only $17 \%$ of that total (Parfeni, 2010), which means that a high number of followers do not necessarily translate to a high number of active followers that are receiving an organization's tweets.

\section{YouTube}

After just four years, YouTube reached one billion views per day, which made it the second highest search engine behind Google, who purchased YouTube in 2006 (Schroder, 2009). This purchase from Google brought advertisement to YouTube by placing advertising on videos with high viewing counts. Similar to other networks, the advertising allowed YouTube to remain a free social media website. Likewise, YouTube channels can be used by organizations to accomplish certain marketing strategies through the use of a YouTube community and video sharing.

Judson Laipply established a company that incorporated a YouTube video that was viewed by 98 million people and became a profitable business for him (Brogan \& Smith, 2009). This example clearly shows the potential that organizations could receive from this social media network. This was the very reason why the 2008 Presidential Candidate Barack Obama used YouTube to make his push toward the White House (Harfoush, 2009). Harfoush (2009) described the concept of leveraging the community's response to YouTube videos as:

An important part of the YouTube community's philosophy is the ability to post a video response. Video responses on Obama's videos led to increased traffic because when someone posted a comment on their own channel, it would encourage those who came across that video response to link to the original speech to see what it was about. This capitalized on existing community behavior to increase traffic and visibility. (p.175)

Organizations can use YouTube in a variety of ways, including launching new products and services, promoting existing ones, and reaching users that could not be reached through traditional marketing efforts. For example, Google released videos of their new product - Google Wave on YouTube - to introduce the product to the market and it received high user viewing rates and interactions (YouTube, 2010). Furthermore, as mentioned above, organizations can embed videos from YouTube on corporate websites, blogs and other social media networks. These examples and tactics show that organizations can successfully integrate YouTube as a marketing strategy.

\section{Use of Social Media in the Context of Promotion for Health-related Facilities}

There are some articles suggesting the usefulness of social media in the context of promotion for fitness facilities. Thackeray, Neiger, Hanson, and McKenzie (2008) suggested that the use of viral social media may be more effective in encouraging others to participate in health promotion efforts and may be more powerful than traditional advertising. When considering college students, the priority population preferences are heavily in favor of use of this approach. It is also important to remember that health promotion budgets may have few dedicated funds for advertising or promotion in general (Thackeray, et al., 2008). Other authors have suggested that social networking sites attract the most users, making them an obvious target for maximizing the reach of health communications (less blog, online support groups). Health communication efforts utilizing the social media will have the broadest reach and impact when targeting younger audiences (Chou, Hunt, Moser, and Hesse, 2009).

Health information on the Internet is largely trusted (Bennett and Glasgow, 2009). The employer sector continues to enhance its wellness programming with increasing emphasis on Internet offerings. There is emerging support for Internet interventions, though this may not be the same as offering wellness services. Although this 
interest in Internet use may be understandable, there may need to be concern about high levels of attrition among users (Bennett and Glasgow, 2009). It is the case that incentive programs have been suggested to help. Selfmonitoring has been found to be an effective strategy for use as well (Bennett and Glasgow, 2009).

\section{PILOT PROJECT}

\section{The Fitness Center}

A pilot project was conducted on the campus of a midwestern university in order to determine whether social media networks could potentially replace traditional marketing efforts as the primary marketing strategy. The study took place at the main student fitness facility and focused on a marketing plan implemented there. The center was selected for this study because the center had devoted the majority of its marketing strategies to traditional media tools (newspaper, radio, brochures, etc.) from its opening to the start of the pilot project. The pilot project reduced the center's traditional marketing spending from $100 \%$ of the total marketing budget to just $5 \%$. That allowed the remaining $95 \%$ of the marketing budget to be used for social media networks within the pilot project marketing plan.

The center implemented a pilot project marketing plan that included introducing the three social media networks of Facebook, Twitter, and YouTube. One goal was to link these social media networks to the main website of the center to promote programs and services. Another goal was to establish a presence in these networks to determine which social media network would be the most effective marketing tool for a promotional contest that was the central component of the marketing plan.

That promotional contest called Viva Wow was implemented as part of the plan. The plan was to utilize a two-month period to evaluate the three social media networks and determine which would be most effective to use in the Viva Wow contest. Table 1 shows the three fitness center social media networks that were created and their two-month participation numbers.

Table 1: Center Social Media Networks

\begin{tabular}{|c|c|}
\hline Network & Users \\
\hline Facebook & 1,200 Fans \\
\hline Twitter & 200 Followers \\
\hline YouTube & Over 1,000 views \\
\hline
\end{tabular}

It was evident that the center Facebook page had the most fans and thus became the central social media network in Viva Wow. Twitter and YouTube were still used to expand the reach, but their goal was strictly to drive traffic to the center Facebook page. The next section describes the Viva Wow contest.

\section{Viva Wow Contest}

The two main components to the Viva Wow contest were the preliminary and final rounds. When two people registered as a team for the free contest, they automatically entered into the preliminary round.

\section{Prelims}

In the prelim round, the goal for each team was to obtain as many Wow Coins as possible. Wow Coins were virtual coins that contestants could earn in a number of ways. In addition to these set programs and services, weekly updates were posted on the Facebook page describing additional ways teams could earn Wow Coins. Wow Coins were tracked through the use of member identification cards and utilizing a simple website tracking program. When a team member swiped their identification card at one of the center's programs or services, the tracking program recorded the name and provided the appropriate Wow Coins to that team member.

All of the weekly Wow Coin team totals were posted on the Facebook page so teams could see where they stood in comparison to others. The preliminarily round lasted ten weeks. Sixty-two teams signed up for the preliminary round in Viva Wow and the top five teams with the most total Wow Coins advanced to the final round. 
Finals

The five teams competed in a video competition to determine the grand prize winner. The finalists were given two weeks to create original videos; at that point they submitted their final videos to the center. Those five videos were then posted on the center Facebook page for one week; and the team with the most "like" votes on their video at the end of the week won the Viva Wow grand prize. In order to receive a vote, a Facebook user had to be a fan of the center Facebook page and click the "like" button below a team's video. The other teams that did not qualify for the final round were able to vote for the videos, but were not eligible for prizes.

\section{RESULTS}

The center pilot project results focus on three key components: 1) change in total student check-in numbers, 2) change in programs and services, and 3) change in social media network participation.

\section{Student Check-In Numbers}

The first results measured were total student check-in numbers for the facility during the two-month period (and three months following). The total student check-in number is determined by how many times student members swiped their identification cards when coming into the center. In order to determine the percent change in total student check-ins, the numbers were compared to the same months in the prior year when traditional marketing efforts were used. Table 2 shows a month-by-month breakdown of student check-ins between the two periods; an increase of $6 \%$ - or nearly 8,000 check-ins - was realized. When enrollment is accounted for, which increased by $3 \%$ over the same period of time, the net student check-in increase was $3 \%$.

Possible reasons for the change will be examined in the discussion section. It is worth noting that the increase occurred during the marketing plan and Viva Wow contest when social media networks were used for the first time at the center.

Table 2: Monthly Student Check-ins

\begin{tabular}{|l|c|c|}
\hline & Year 1 & Year 2 \\
\hline Month One & 9,167 & 32,072 \\
\hline Month Two & 36,340 & 33,005 \\
\hline Month Three & 34,223 & 32,706 \\
\hline Month Four & 29,436 & 19,479 \\
\hline Month Five & 17,903 & $\mathbf{1 3 4 , 9 8 1}$ \\
\hline Total & $\mathbf{1 2 7 , 0 6 9}$ & $6 \%$ \\
\hline & & \\
\hline Change & & 13,172 \\
\hline & & $3 \%$ \\
\hline Enrollment & 12,748 & \\
\hline
\end{tabular}

\section{Program Services Numbers}

The second set of results totaled were the participation numbers for the program and services at the center. The three main center programs and services that are offered to members are the Culinary Corner, Group Exercise and Specialty Exercise. Table 3 shows participation numbers compared to the same months in the previous year. The second column reflects the total increase in participation numbers in three different program services between the two periods. The third column shows the total unique participation count and the last column shows the average number of classes attended per person. 
Table 3: Student Participation Numbers

\begin{tabular}{|l|c|c|c|}
\hline & Total Participation Count & Unique Participation/Area & $\begin{array}{c}\text { Average No. Classes } \\
\text { Attended/Person }\end{array}$ \\
\hline Culinary Corner - Year One & 41 & 29 & 1.41 \\
\hline Culinary Corner - Year Two & 336 & 80 & 4.20 \\
\hline \% Increase & $720 \%$ & $176 \%$ & $197 \%$ \\
\hline Group Exercise - Year One & 3019 & 884 & 3.42 \\
\hline Group Exercise - Year Two & 4776 & 1,068 & 4.47 \\
\hline \% Increase & $58 \%$ & $21 \%$ & $31 \%$ \\
\hline Specialty Exercise - Year One & 112 & 18 & 6.22 \\
\hline Specialty Exercise - Year Two & 315 & 40 & 7.88 \\
\hline \% Increase & $181 \%$ & $122 \%$ & $27 \%$ \\
\hline
\end{tabular}

These results indicate increases in every category of each program service between the two years. The changes will be examined further in the discussion section, but first the social media network results will be reviewed.

\section{Social Media Networks}

Finally, the results from the center's social media networks were determined. The total number of fans increased from just over 1,200 prior to the investigation period to nearly 3,600 at the end of the study period. The main increase occurred during the week of the video voting in the final week of Viva Wow.

Twitter and YouTube were the two social media networks that did not show a noteworthy increase over the span of the marketing plan. The center Twitter followers increased from 200 to 300 while the center YouTube Channel views increased from 1,000 to 1,300 during the same period of time. Possible reasons for this will be discussed in the next section.

\section{DISCUSSION}

When reviewing the student check-in results, an increase of nearly 8,000 student check-ins between the two years was a favorable increase for the center. This increase came from the fact that either new students were using the center or existing students were utilizing the facility on a more frequent basis. In either scenario, a positive outcome resulted with a $6 \%$ student check-in increase.

The program services had unexpected results when comparisons were made between the two years for the three main areas at the center. The results showed that the Culinary Corner experienced a $720 \%$ increase in participation between the two periods with numbers increasing from 41 to 336. The unique participants rose from 29 to 80 and average attendance per person improved from 1.41 to 4.20 with percentage increases of $176 \%$ and $197 \%$, respectively. Group Exercise classes saw an increase from 3,019 to 4,776 in the total participation count ,which was a difference of $58 \%$ for the positive and an increase of $31 \%$ in average attendance per person. Lastly, Specialty Exercise increased from 112 to 315 total participants, which was a positive increase of $181 \%$, while the average attendance per person for Specialty Exercise increased by $31 \%$. These results show that not only were more students using these services, they were also attending on a more frequent basis.

The social media network participation numbers showed mixed results. The center Facebook page tripled the number of fans from 1,200 to 3,600, but the main increase came during the final week of the Viva Wow contest. The center Twitter page and YouTube Channel experienced small and seemingly insignificant increases over the period of the marketing plan. Since these networks were implemented for the first time for this study, no historical data can be used to compare results.

One possible explanation for the increases in student check-ins and the program services could be the increase in participation from the Viva Wow contest. The fact was Wow Coins were incentives to using the center and the different program services. For example, a team member would receive 100 points for exercising at the center and up to 500 points per center class attended at one of the program services. This could have translated into 
an increase in motivation to use the center and services on a more regular basis, and thus be the reason for the increases in both of these areas. On the other hand, the Viva Wow contest had only 120 participants, which could be seen as an insignificant number compared to the amount of total student check-ins over the span of the contest. However, Viva Wow contestants were active in the program services offered at the center, which needed a much smaller increase of regular participants to show a major change. The Viva Wow contest most likely had a positive impact on both the student check-in numbers and the program service participation numbers, with the latter receiving better increases.

Another explanation for the increases in student check-ins and program services could have been the new marketing plan and strategies to use social media networks. The extent to which social media networks helped the increases is hard to determine because the network participation did not increase steadily with the other numbers. As mentioned, the Facebook page grew mostly at the beginning and end of the marketing plan, and the Twitter page and YouTube channel saw only minimal growth. The reason for these differing social media networks results could have been the team members' preference for receiving updates and viewing videos on one location - the Facebook page - versus the two locations of Twitter and YouTube. It was interesting to observe the spike in Facebook fans at the end of the Viva Wow contest during the voting week. This momentous swell of fans was largely due to the fact that the five finalist teams of Viva Wow were promoting their videos on the center Facebook page and driving traffic to the network during that week. The main advantage there was that the members were advocating for the center by actively promoting the page and their videos. In addition, voters needed to become fans of the center to place a vote for their favorite finalist video. The main advantages of using Facebook in this manner were positive public relations, exposure and an increased fan base that attracted members that would have otherwise been unobtainable.

In summary, it is evident that at least the use of Facebook and the Viva Wow contest, which were the core of the center marketing plan, played major roles in the change in numbers between the two years. From the health promotion data provided earlier, it is clear that interactive social media is going to be the most successful in targeting younger audiences (Chou, et.al., 2009; Thackeray, et.al., 2008). This was verified in the effectiveness of the use of Facebook and the Viva Wow contest, but not as much in the Twitter and YouTube cases.

\section{RECOMMENDATIONS FOR FURTHER STUDY}

- The center marketing plan involved a grand prize for the Viva Wow contest of a trip for two to Las Vegas, Nevada. By doing this, the center had to reduce its traditional marketing budget to $5 \%$ of the total - down from $100 \%$ - while increasing the marketing budget for social media strategies and prizes from $0 \%$ to roughly $95 \%$ of the total marketing budget. Another organization may want to conduct a marketing campaign in the future that has a balance of traditional and social marketing strategies with a 50/50 split of the budget on the two and compare the results to this case study.

- Another variation would be to maintain traditional marketing and supplement it with a couple of the new social media networks.

- $\quad$ The final week of the Viva Wow contest saw the greatest interaction and increase in the center Facebook page. Another approach would be to replicate the final week of that contest on smaller more frequent levels. Instead of having a voting system set up at the end of a contest, an organization may want to try that in the beginning of a campaign or throughout a certain time period. The goal of this is to increase participation in the social media networks, so the organizational goals must be taken into account before trying such a strategy.

- $\quad$ The Viva Wow contest seemed to work well for the center audience; however, other organizations may want to try a different approach and contest themes; i.e., other prizes and incentives that could be used to motivate the audience.

\section{CONCLUSION}

In conclusion, there is a continuing and significant marketing transformation and movement toward the increased consumer adoption and usage of social media networks. The increase led organizations to explore the marketing possibilities the networks offered, in particular, the social media networks of Facebook, Twitter and 
YouTube. As organizations began using these networks, they evaluated whether social media networks could become a primary marketing strategy and reduce or ultimately replace traditional marketing efforts. This new focus on social media networks represented an organizational shift in marketing that has been seen throughout history with the introductions of newspaper, radio, television and internet.

Could social media networks be the next big transformation in the evolution of organizational marketing? Only time will tell, but the results of the center pilot project, combined with the shift in consumer behavior toward these networks, argues strongly for the organizational support of that marketing transformation.

\section{AUTHOR INFORMATION}

Mr. Joseph Field is an MBA graduate of the University of North Dakota. E-mail: bfield23@ hotmail.com

Dr. Dennis Elbert, UND Dean of the College of Business and Public Administration and Professor of Marketing, received his BSBA degree from UND, his MS in Marketing and Ph.D. from the University of Missouri - Columbia. He has been active in reviewing institutions for various levels of AACSB accreditation. Elbert has served or is serving on several local and regional boards of directors. His many journal publications include the Journal of Small Business Management, Journal of Marketing Education, Swiss Journal of Small Business Research, Journal of Professional Services Marketing and Services Marketing Quarterly. E-mail: delbert@business.und.edu (Corresponding author)

Dr. Steve Moser is a Professor of Management and the Associate Dean at the College of Business and Public Administration at the University of North Dakota. He has research interests pertaining to entrepreneurship, human resources and organizational behavior. Dr. Moser's research work has been published in the Journal of Small Business Management, Public Personnel Management, Journal of Education for Business, Journal of Applied Business Research, Entrepreneurship and Regional Development, and Journal of International Information Management. E-mail: smoser@business.und.edu

\section{REFERENCES}

1. Bennett, G.G. \& Glasgow, R.E. (2009). The delivery of public health interventions via the Internet: Actualizing their potential. Annual Review of Public Health, 30, 273-292.

2. Brogan, C., \& Smith, J. (2009). Trust agents: Using the web to build influence, improve reputation, and earn trust. New York: John Wiley \& Sons.

3. Chou, W.S., Hunt, Y.M., Beckjord, E.B., Moser, R.P., and Hesse, B.W. (2009). Social media use in the United States: Implications for Health Communication. Journal of Medical Internet Research, 11(4), e48.

4. Facebook, Inc. (2010). Retrieved March 28, 2010 from http://www.facebook.com

5. Foux G. (2006, May 8). Consumer-generated media: Get your customers involved. Brand Strategy, 38-39.

6. Gaudin, S. (2010, January 26). Twitter now has 75M users; most asleep at the mouse. Computer World. Retrieved March 27, 2010 from http://bit.ly/twitter75million

7. Hampton, K.N., Goulet, L.S., Rainie, L., and Purcell, K. (2011). Social networking sites and our lives: How people's trust, personal relationships, and civic and political involvement are connected to their use of social networking sites and other technologies. Retrieved June 30, 2011 from http://www.pewinternet.org/Reports/2011/ /media/Files/Reports/2011/PIP\%20\%20Social\%20networking\%20sites\%20and\%20our\%20lives.pdf

8. Harfoush, R. (2009). Yes we did: An inside look at how social media built the Obama brand. Berkeley, CA: New Riders.

9. Morris, T. (2010). All a Twitter: A personal and professional guide to social networking with Twitter. Indianapolis, IN: QUE.

10. Parfeni, L. (2010, January 27). Twitter user numbers at 75 million. SoftPedia. Retrieved March 27, 2010 from http://bit.ly/twitter17percent

11. Qualman, Erik. (2009). Socialnomics: How social media transforms the way we live and do business. New York: John Wiley \& Sons. 
12. Sarno, D. (2009, February 18). Twitter creator Jack Dorsey illuminates the site's founding document: Part I. Los Angeles Times. Retrieved March 27, 2010 from http://latimesblogs.latimes.com/technology/2009/02/twitter-creator.html

13. Schroder, S. (2009, October 5). YouTube reaches one billion views per day. Mashable. Retrieved March 27, 2010 from http://mashable.com/2009/10/09/youtube-billion-views/

14. Thackeray, R., Neiger, B.L., Hanson, C.L., \& McKenzie, J.F. (2008). Enhancing promotion strategies with social marketing programs: Use of web 2.0 social media. Health Promotion Practice, 9, 338-343.

15. Twitter, Inc. (2010). Retrieved March 27, 2010 from http://twitter.com/about

16. UMass Dartmouth Center for Marketing Research Blog, Social media continues to be used with higher education recruitment. Retrieved June 29, 2011, from http://centerformarketingresearch.wordpress.com/2010/05/18/social-media-continues-to-be-used-withhigher-education-recruitment

17. YouTube, Inc. (2010). Retrieved March 27, 2010 from http://youtube.com 
NOTES 